Vulnerability of marine forests to temperature and UV radiation: effects on the recruits

Alba Verges ${ }^{1}$, Sonia de Caralt ${ }^{1,2}$, Jana Verdura ${ }^{1}$, Jorge Santamaria ${ }^{1}$, Enric Ballesteros ${ }^{2}$, Emma Cebrian ${ }^{1}$

${ }^{1}$ GRMAR Institute of Aquatic Ecology, University of Girona, Girona, Catalonia, Spain

${ }^{2}$ Centre d'Estudis Avançats de Blanes, Consejo Superior de Investigaciones Cientificas, Blanes, Catalonia, Spain

Corresponding Author:

Alba Verges ${ }^{1}$

E mail address: alba.verges@udg.edu 


\section{VULNERABILITY OF MARINE FORESTS TO TEMPERATURE AND UV RADIATION: EFFECTS ON THE RECRUITS}

Vergés, A. ${ }^{1}$, de Caralt, S. ${ }^{1}$, Verdura, J. ${ }^{1}$, Santamaria, $J^{1}$, Ballesteros E. ${ }^{2}$ \& E., Cebrian ${ }^{1}$

${ }^{1}$ GRMAR Institute of Aquatic Ecology, University of Girona, Girona, Catalonia, Spain

${ }^{2}$ Centre d'Estudis Avançats de Blanes, Consejo Superior de Investigaciones Cientificas, Blanes, Catalonia, Spain

Macroalgal forests provide essential ecosystem services and are home for a wide variety of organisms. The genus Cystoseira includes several species, each being dominant in a determined range of environmental variables. Most Cystoseira species are Mediterranean endemisms and show clear signs of regression across all their distribution range. Even if these regressions are well known, the ultimate drivers are still not clearly understood. Here we explore experimentally how climate change affects two Cystoseira species adapted to contrasting hydrodynamic regimes: exposed (C. mediterranea) and sheltered (C. crinita). Viability of Cystoseira populations strongly rely on their recruitment. We focus in the recruitment survival of both species, at normal $\left(21^{\circ} \mathrm{C}\right.$ to $\left.25^{\circ} \mathrm{C}\right)$ and high temperatures $\left(28^{\circ} \mathrm{C}\right)$, and at increased rates of UV radiation (PAR and PAR+UVA+UVB).

Results show that normal temperatures did not affect Cystoseira recruitment, whereas unusual high temperatures $\left(28^{\circ} \mathrm{C}\right)$ lead to the death of settlers of both species. In contrast, UVA-UVB radiation showed a cumulative impact on the recruitment survival, strongly impairing the development of recruits growing at all temperature conditions. Our results are the first experimental evidences of climate strongly compromising the viability of Cystoseira forests. 
(c) 2018 Verges et al. This is an open access article distributed under the terms of the Creative Commons Attribution License:

http://creativecommons.org/licenses/by/4.0/ (the "License"), which permits unrestricted use, distribution, reproduction and adaptation in any medium and for any purpose provided that it is properly attributed. For attribution, the original author(s), title, publication source (PeerJ Preprints) and either DOI or URL of the article must be cited. Notwithstanding the ProQuest Terms and Conditions, you may use this content in accordance with the terms of the License. 